\title{
IMPROVING AIR QUALITY AND HUMAN HEALTH: AN APPROACH BASED ON ARTIFICIAL NEURAL NETWORKS
}

\author{
HELDER RELVAS ${ }^{1}$, JOANA FERREIRA ${ }^{1}$, DIOGO LOPES ${ }^{1}$, SANDRA RAFAEL $^{1}$, \\ SUSANA MARTA ALMEIDA ${ }^{2} \&$ ANA ISABEL MIRANDA ${ }^{1}$ \\ ${ }^{1}$ CESAM \& Department of Environment and Planning, University of Aveiro, Portugal \\ ${ }^{2}$ Centro de Ciências e Tecnologias Nucleares (C2TN), Instituto Superior Técnico, \\ Universidade de Lisboa, Portugal
}

\begin{abstract}
In 2015 up to $30 \%$ of Europeans were living in cities with air pollutant levels exceeding European Union (EU) air quality standards, and around $95 \%$ were exposed to high concentrations, namely particulate matter (PM), deemed damaging to health accordingly to the World Health Organization (WHO) Air Quality Guidelines. In order to reduce air pollution effects, particularly in cities where the majority of the population lives, it is important to define effective planning strategies for air quality improvement. For this purpose, the ongoing project LIFE Index-Air aims to develop an innovative and versatile decision support tool for policy makers, based on an integrated modelling approach, from emissions to health effects, which will help to identify measures to improve air quality, reducing PM levels, and quantitatively assess their impact on the health and well-being of the populations. Five European urban areas will be considered, Lisbon (Portugal), Porto (Portugal), Athens (Greece), Kuopio (Finland) and Treviso (Italy) at high spatial and temporal resolution, covering $\mathrm{PM}_{10}, \mathrm{PM}_{2.5}$ and metal elements regulated by EU legislation. For now, the WRF-CAMx air quality modelling system was applied to the Portuguese domains with a spatial resolution of $0.01^{\circ}(\sim 1 \mathrm{~km})$ for 2015 . The EMEP emission inventory for 2015 with a spatial resolution of $0.1^{\circ}$ and including metal species was considered. For the finest resolution domains (urban) the EMEP emissions were disaggregated to $1 \mathrm{x} 1$ $\mathrm{km}^{2}$, based on spatial proxies and emission sources locations. This paper shows the preliminary air quality modelling results, and presents the methodology, based on Artificial Neural Networks (ANN), which will allow to quickly test different measures to improve air quality and to reduce air pollution effects.
\end{abstract}

Keywords: PM10, health, WRF-CAMx, air quality modelling, Artificial Neural Networks.

\section{INTRODUCTION}

Good air quality is still a challenge in the world and in Europe in particular. The latest "Air quality in Europe" report, delivered by the European Environment Agency [1], indicates that air quality policies have led to many improvements. However, European urban populations are still partially exposed to air pollution that surpasses European standards and, principally, the World Health Organization (WHO) Air Quality Guidelines, with considerable impacts, on both human health and the environment [2]-[4].

The concentrations of air pollutants result from a range of atmospheric processes including atmospheric transport, mixing and chemical transformations. Nowadays, nitrogen dioxide $\left(\mathrm{NO}_{2}\right)$, tropospheric ozone $\left(\mathrm{O}_{3}\right)$ and particulate matter $(\mathrm{PM})$, in particular the ones with an aerodynamic equivalent diameter less than $2.5 \mu \mathrm{m}\left(\mathrm{PM}_{2.5}\right)$, are strongly affecting human health and are associated with increased mortality and morbidity [5]. Estimates of the health impacts attributable to exposure to air pollution indicate that $\mathrm{PM}_{2.5}$ concentrations in 2014 were responsible for about 399,000 premature deaths originating from long-term exposure in EU-28. The estimated impacts on the population of exposure to $\mathrm{NO}_{2}$ and $\mathrm{O}_{3}$ concentrations in 2014 were around 78,000 and 14400 premature deaths per year, respectively [1]. 
Even if there are many possible interventions that can be made at the city scale, through measures, such as investment in public transport, low emission zones (LEZ), changes in heating and cooling systems, it is difficult for policy-makers to quickly assess the consequences of measures on local air quality. The ongoing LIFE Index-Air project (http://www.lifeindexair.net) intends to develop an innovative and versatile decision support tool for policy makers that will help to identify measures to improve air quality and quantitatively assess their impact on the health and well-being of the population. The tool will be tested by its implementation in 5 European cities, Lisbon, Porto, Athens, Kuopio and Treviso. The present work is part of this research project and aims to present the first modelling results and the methodology used to facilitate the assessment of different strategies to improve air quality.

The paper is organised as follows. In Section 2, the modelling approach is described in detail. Section 3 focuses on the analysis of the first modelling results and the Section 4 details the methodology used inside the tool. Finally, in Section 5, the main conclusions are summarized.

\section{THE MODELLING SYSTEM AND ITS SETUP}

Numerical modelling has become a fundamental tool to support decision makers on air quality management due to its capacity to estimate atmospheric pollutants concentrations over the entire region of interest, taking into account complex and non-linear physic and chemical mechanisms that characterize the atmosphere, as well as to evaluate the efficiency of emission reduction scenarios.

\subsection{The WRF-CAMX modelling system}

The air quality modelling system applied in this study includes the Weather Research and Forecasting (WRF, version 3.7.1) model (WRF) [6] and CAMx (Comprehensive Air Quality Model with Extensions) chemical transport model [7]. Its input-output structure is schematized in Fig. 1. The WRF model was developed by the National Center for Atmospheric Research (NCAR) and is a next generation mesoscale numerical weather prediction system designed to serve both operational forecasting and atmospheric research needs. CAMx is a three-dimensional (3D) chemical transport model suited for the simulations of the emission, dispersion, chemical reactions, and removal of pollutants in the troposphere based on the integration of the continuity equation for each chemical species on a system of nested 3D grids. This modelling system has been extensively applied for Portugal and worldwide [8]-[11].

\subsection{Modelling setup and application}

The WRF-CAMx air quality modelling system was selected to be applied under Index-Air according to its suitability to simulate the meteorological conditions and the atmospheric concentrations of particulate pollutants for the study regions, including the speciation into $\mathrm{Ni}$ (Nickel), As (Arsenic), $\mathrm{Cd}$ (Cadmium), $\mathrm{Pb}$ (Lead), as the elements regulated by the air quality legislation. It was applied to a past year, 2015, for validation with data acquired in air quality monitoring stations operating on a regular basis in the study regions.

Meteorological inputs to the chemical simulations were driven by the meteorological model WRF, forced by ERA Interim reanalysis data from ECMWF (European Centre for Medium Range Weather Forecast) at 6 hours and 0.75 degrees temporal and spatial resolution, respectively. 


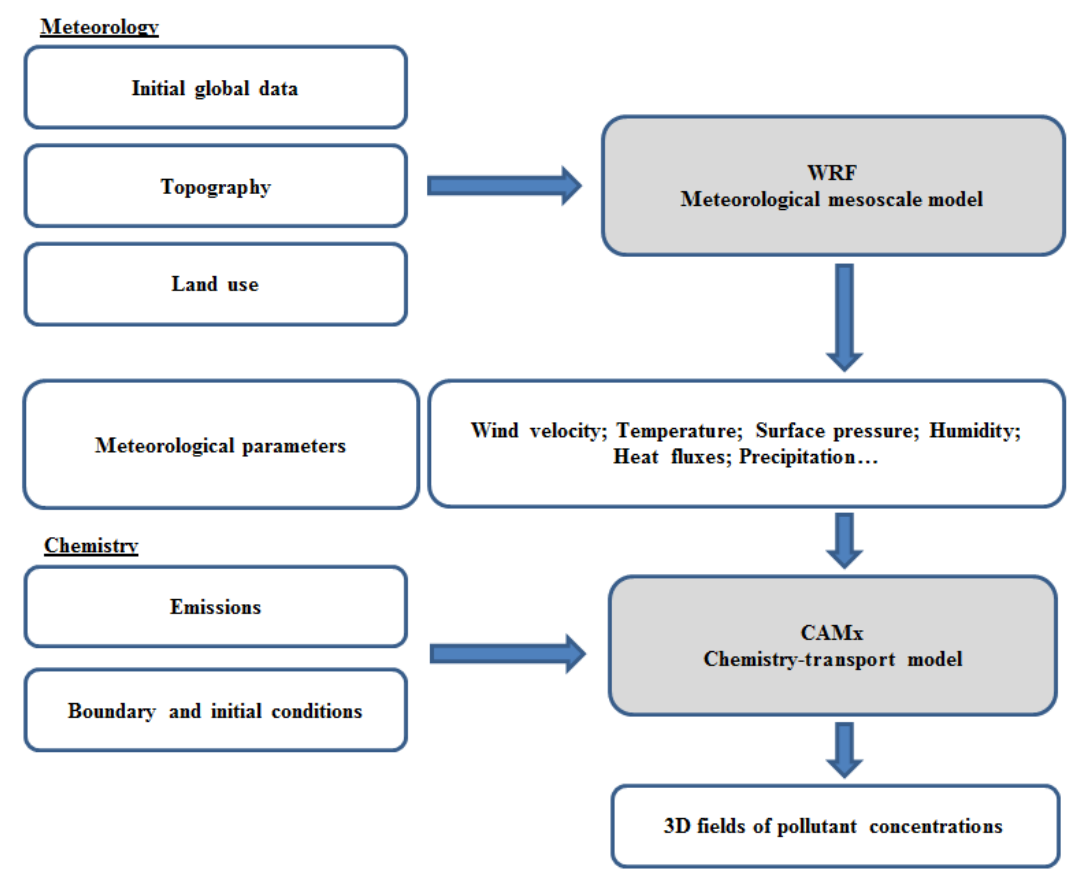

Figure 1: The input-output structure of the modelling system WRF-CAMx applied in this study.

Initial and boundary conditions for the first domain are provided by the global chemical model MOZART [12] with a time resolution of 6 hours.

Anthropogenic emissions were taken from the most recent European emission inventory based on Member States submissions for the year 2015. The EMEP inventory, with an horizontal resolution of $0.1^{\circ}$ (approximately $10 \mathrm{~km}$ ), comprising annual emission totals by activity sector for gases and particulate species including metals, was disaggregated to the case study modelling domains and speciated into the CB6 chemical mechanism gaseous species and into the default particulate species considered by CAMx. The chemical mechanism description and treatment was adapted to additionally include the metal species as inert particles.

In order to improve the spatial resolution of the emission inventory, the emissions were spatially disaggregated to $1 \mathrm{~km}$ resolution considering different proxies. The following Selected Nomenclature for Air Pollution (SNAP) activities were considered: public power stations (SNAP1); commercial and residential combustion (SNAP2); industrial combustion (SNAP3); production processes (SNAP4); extraction and distribution of fossil fuels and geothermal energy (SNAP5); solvent and other product use (SNAP6); road transport (SNAP7); other mobile sources and machinery (SNAP8); waste treatment and disposal (SNAP9), agriculture (SNAP10). In particular, in case of SNAP1 the specific location of public power stations was considered, in SNAP2 a "bottom up" approach was used, taking into account the wood consumption per district, the type of residential combustion equipment, and emission factors from the Portuguese Agency for the Environment (APA) [13] (see Fig. 2). For SNAP3 and 4 the location of industries was considered based on national land use data. For SNAP5 and 6 the buildings locations, using the information from 

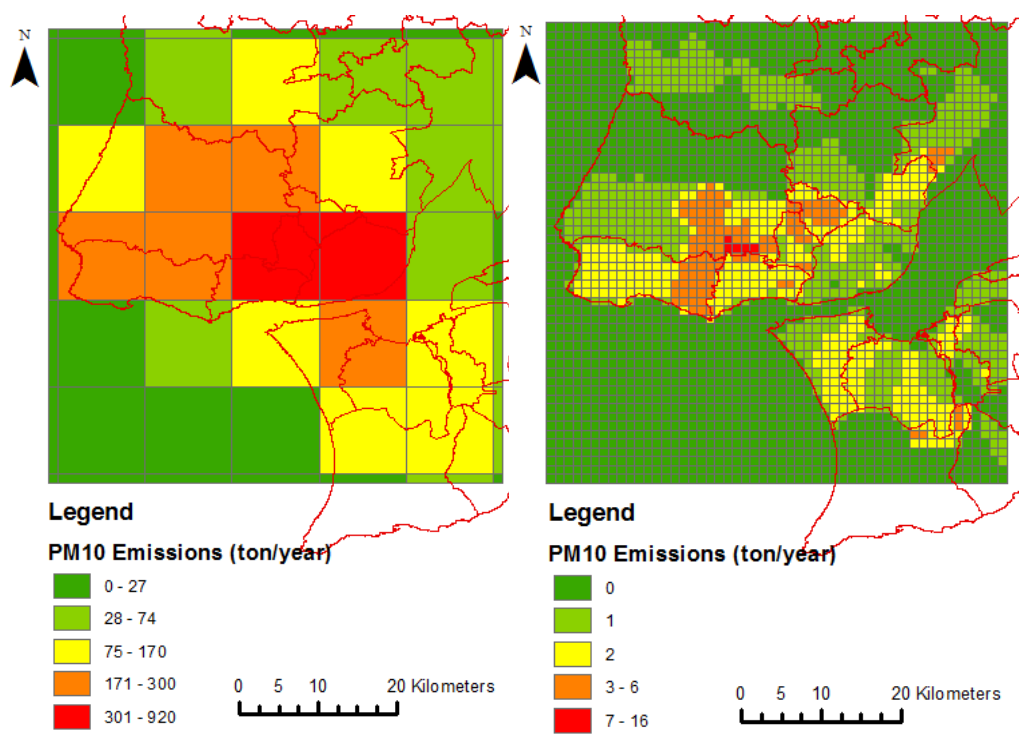

Figure 2: Total $\mathrm{PM}_{10}$ residential combustion emissions for Lisbon domain considering EMEP (left) and spatial disaggregation (right). The reference year is 2015.

the OpenStreeMap was considered. Regarding SNAP7, road traffic emissions were estimated applying the Transport Emission Model for Line Sources (TREM) [14] and using traffic counts, average vehicle speed, and statistical fleet data. For SNAP8 the airport and port location were considered. Lastly the national land use data regarding farming fields was used to spatially disaggregate emissions of SNAP10. Fig. 2 displays the original EMEP emissions for SNAP2 (resolution of $10 \mathrm{~km}$ ) on the left and the disaggregated ones on the right $(1 \mathrm{~km}$ of horizontal resolution) for the Lisbon case study domain.

Fig. 2 shows that residential emissions are mainly concentrated in Sintra, Cascais, Odivelas, and Amadora municipalities. In Lisbon municipality the emissions are more reduced due the use of different heating systems. Even using a different approach, the EMEP inventory with an horizontal resolution of 0.1 degrees is able to generically represent the spatial distribution of $\mathrm{PM}_{10}$ emissions from residential combustion sector. The high spatial desegregated emissions $\left(1 \times 1 \mathrm{~km}^{2}\right)$ from the different SNAP macrosectores were then used as input to WRF-CAMx to simulate the concentration fields (1-hour resolution) over Lisbon.

\section{FIRST MODELLING RESULTS}

In this section the WRF validation results for the Portuguese domains (Porto and Lisbon) are presented (Fig. 3) as well as the WRF-CAMx results for Lisbon (Fig. 4).

\subsection{Meteorology}

The WRF was applied for the five Index-Air case studies following a two-way nesting technique in the WRF model for three domains (Fig. 3): D-1 with $25 \mathrm{~km}$ spatial resolution centered in Europe a covering also Northern Africa and part of the Atlantic Ocean, and it is intended to capture synoptic features and general circulation patterns. D-2, with a spatial resolution of $5 \mathrm{~km}$, comprises Portugal, and the innermost domain (D-3) reaching $1 \mathrm{~km}$ resolution over each urban area. 


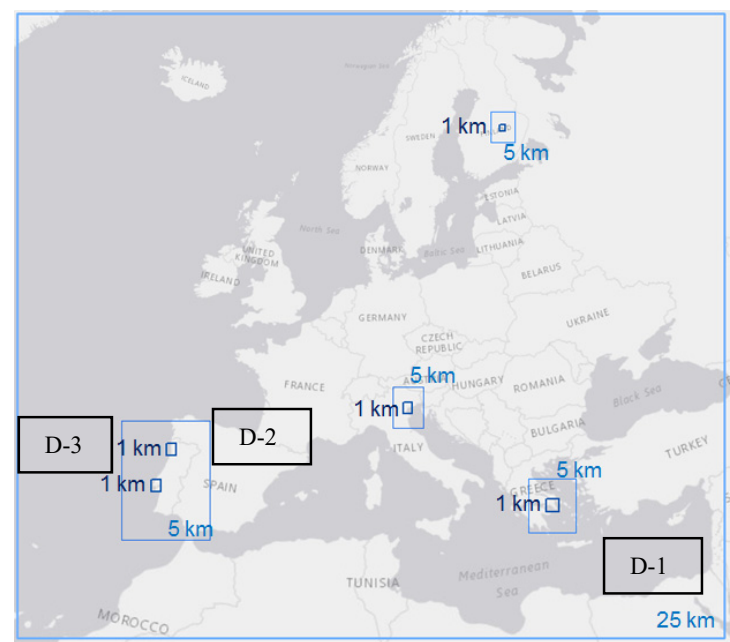

Figure 3: WRF domains used in the simulations: D-1 covering Europe, with a resolution of $25 \mathrm{~km}, \mathrm{D}-2$ with a resolution of $5 \mathrm{~km}$ and reaching $1 \mathrm{~km}$ in the innermost domains (D-3) which covers the different cities.

Statistical results from the evaluation of WRF outputs for Lisbon and Porto are presented in Table 1. The meteorological stations in Lisbon (Gago Coutinho) and Porto (Pedras Rubras) are both situated in the Atlantic coastal zone. The statistical parameters BIAS (tendency of a statistic to overestimate or underestimate a parameter), NMSE (Normalised Mean Square Error) and $\mathrm{r}$ (coefficient of correlation) were computed.

The results indicate a good agreement between the model estimates and the measurements in both cities, with a better performance for temperature. The WRF tends to underestimate temperature and wind speed in the Porto domain, and to overestimate these parameters in Lisbon. In general, WRF shows a good performance simulating the meteorological data, which is in agreement with other studies where the WRF model was applied for Portugal.

\subsection{Air quality}

Fig. 4 shows the spatial distribution of $\mathrm{Pb}$ and $\mathrm{PM}_{10}$ monthly average concentrations over the Lisbon domain for January 2015. The small dots over the map represent the air pollution measurements.

Table 1: Statistical analysis of WRF model results for Porto and Lisbon meteorological stations data considering the temperature and wind speed for January 2015.

\begin{tabular}{lcccccc}
\hline & \multicolumn{7}{c}{ Statistical Parameters } \\
& Porto - Pedras Rubras & \multicolumn{4}{c}{ Lisbon - Gago Coutinho } \\
\hline Variable & BIAS & NMSE & r & BIAS & NMSE & $\mathrm{r}$ \\
\hline Temperature $\left({ }^{\circ} \mathbf{C}\right)$ & -0.05 & 0.01 & 0.96 & 0.03 & 0.01 & 0.97 \\
Wind speed $(\mathbf{m} / \mathbf{s})$ & -0.58 & 0.12 & 0.73 & 0.16 & 0.03 & 0.89 \\
\hline
\end{tabular}




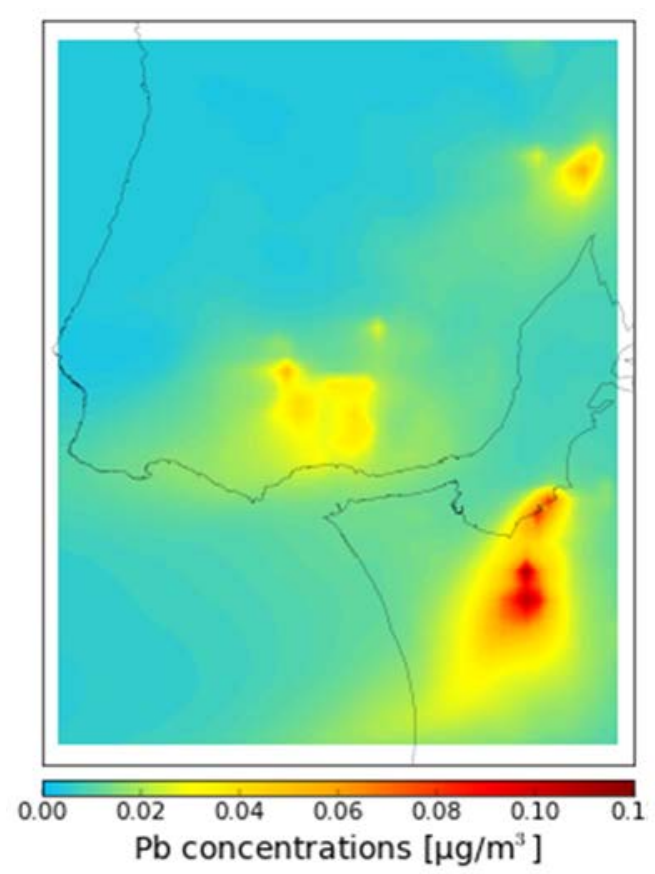

(a)

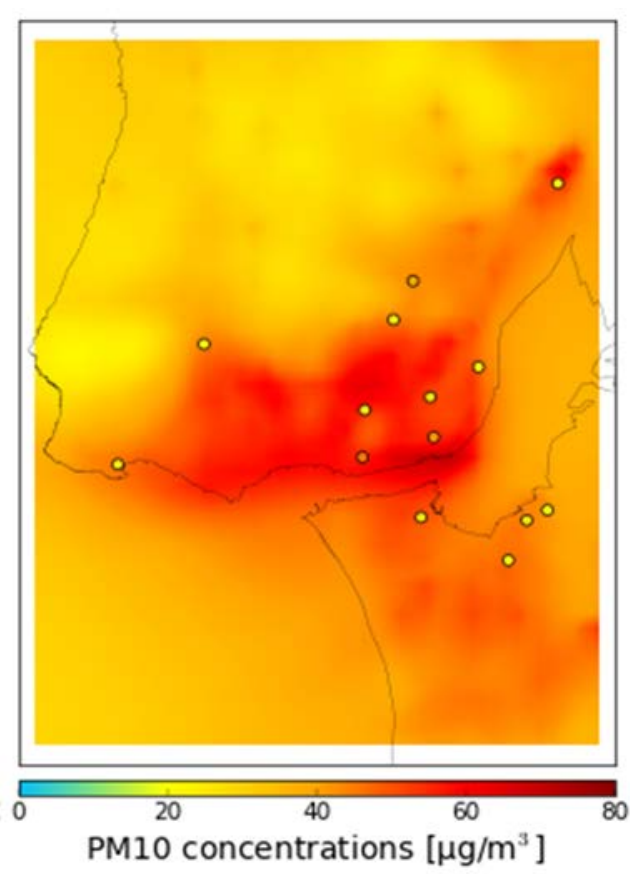

(b)

Figure 4: Monthly average concentrations of $\mathrm{Pb}(\mathrm{a})$ and $\mathrm{PM}_{10}$ (b) over the Lisbon domain for January 2015.

It is possible to observe that over the Lisbon domain there is an area where the $\mathrm{Pb}$ concentration is higher (up to $0.1 \mu \mathrm{g} / \mathrm{m}^{3}$ ), the Seixal municipality where the main steel plant of Portugal is located. The remaining domain area is characterized by very low concentrations, taking in account that the air quality annual limit value for $\mathrm{Pb}$ is $0.5 \mu \mathrm{g} / \mathrm{m}^{3}$.

In relation to $\mathrm{PM}_{10}$ the highest concentration values can be found over Lisbon municipality. These can be related with higher traffic emissions compared to other surrounding municipalities. The comparison with measurements (small dots) shows that the modelling system is generically overestimating the $\mathrm{PM}_{10}$ concentrations.

\section{THE METHODOLOGY USED WITHIN THE TOOL}

Air quality modelling simulations by means of WRF-CAMx cannot directly be used inside the Index-Air management tool to simulate the link between precursor emissions and air quality indexes due to their computational time. Aiming to integrate the air quality and exposure components in the tool, a new approach was defined. Artificial Neural Networks (ANN) will be used to simulate the nonlinear source-receptor relationship between concentrations and the emission of precursors.

To identify ANN it is first necessary to select the model type, architecture and an input shape adequate to the domain under study and, then, to identify a set of emissionconcentration scenarios, that need to be simulated using WRF-CAMx. When figuring out the most suitable input shape it is assumed that the air quality index (AQI) (e.g. annual mean $\mathrm{PM}_{10}$ concentration) values in a given cell can also depend on the precursor emissions in 
distant cells. A second key factor, to be taken into account, concerns dominant wind directions. A technique already presented in literature [15] allows considering these two relevant aspects by aggregating the emissions from cells belonging to four triangular slices, located around the cell for which the AQI has to be computed.

This configuration has the advantage of being adjustable to different conditions by modifying the dimensions of the quadrants. After defining the input shapes, for the 5 IndexAir cities, a minimum set of WRF-CAMx simulations is required to provide data for the ANN calibration and validation. Given the high flexibility of the surrogate model structure adopted in this work (feed-forward neural network), and based on previous works, we estimate that a series of 10 emission reduction scenarios allows identifying the ANN parameters with sufficient accuracy. This minimum number of scenarios has to reproduce all the possible precursor emissions variations.

Finally, after training, the trained ANN will be uploaded in the Index-Air tool (as a .csv file) allowing a quick estimation of air pollutant concentrations values based on a variation on precursor emissions, for each one of the 5 cities.

\section{SUMMARY AND CONCLUSIONS}

This work shows the first results and the applied overall methodology used to develop an innovative and versatile decision support tool for policy makers, based on an integrated modelling approach. The numerical modelling approach was used to simulate air quality over Lisbon $\left(1 \times 1 \mathrm{~km}^{2}\right)$. Modelling results point out that the WRF-CAMX modelling system is able to reasonably simulate meteorology and concentration fields over Lisbon, making possible to continue the simulation of emission reduction scenarios in order to provide inputs to ANN training and validation.

The decision support tool will be able to provide air quality maps and to estimate health impacts allowing testing quickly several abatement measures. Despite the potential of this kind of tools, action on air quality also requires much stronger and regular discussion between local and national authorities, and integrated approaches combining different policy areas.

\section{ACKNOWLEDGEMENTS}

This work was supported by the European Union's LIFE Programme in the framework of the Index-Air LIFE15 ENV/PT/000674 project. Thanks, are also due for the financial support to FCT/MEC through national funds, and the co-funding by the FEDER, within the PT2020 Partnership Agreement and Compete 2020, for the FUTURAR project (PTDC/AAGMAA/2569/2014 - POCI-01-0145-FEDER-016752), and for the post doc grant of J. Ferreira (SFRH/BPD/100346/2014) and PhD grants of H. Relvas (SFRH/BD/101660/2014).

\section{REFERENCES}

[1] EEA, Air Quality in Europe - 2017 report, EEA Report No 13/2017, European Environment Agency, 2017.

[2] Costa, S. et al., Integrating health on air quality assessment - review report on health risks of two major european outdoor air pollutants: $\mathrm{PM}$ and $\mathrm{NO}_{2}$. J Toxicol Environ Health B Crit Rev, 17(6): pp. 307-430, 2014.

[3] Lelieveld, J., Evans, J.S. Fnais, M. Giannadaki, D. \& Pozzer, A., The contribution of outdoor air pollution sources to premature mortality on a global scale. Nature, 525(7569), p. 367, 2015.

[4] Newby, D.E. et al., Expert position paper on air pollution and cardiovascular disease. European Heart Journal, 2014. 
[5] WHO, Health risks of air pollution in Europe-HRAPIE project recommendations for concentration-response functions for cost-benefit analysis of particulate matter, ozone and nitrogen dioxide, World Health Organization Regional Office for Europe: Geneva, Switzerland, 2013.

[6] Skamarock, W.C. \& Klemp, J.B., A time-split nonhydrostatic atmospheric model for weather research and forecasting applications. Journal of Computational Physics, 227(7), pp. 3465-3485, 2008.

[7] Environ, M., User's Guide to the Comprehensive Air Quality Model with Extensions (CAMx) Version 5.20, 2009.

[8] Coelho, M.C. et al., Assessment of potential improvements on regional air quality modelling related with implementation of a detailed methodology for traffic emission estimation. Science of The Total Environment, 470-471, pp. 127-137, 2014.

[9] Martins, H. et al., The role of ammonia on particulate matter pollution over Portugal. International Journal of Environment and Pollution, 57(3)-(4), pp. 215-226, 2015.

[10] Wang, X., Wei, W., Cheng, S., Li, J., Zhang, H. \& Lv, Z., Characteristics and classification of $\mathrm{PM}_{2.5}$ pollution episodes in Beijing from 2013 to 2015. Science of The Total Environment, 612, pp. 170-179, 2018.

[11] Shahbazi, H., Ganjiazad, R., Hosseini, V. \& Hamedi, M., Investigating the influence of traffic emission reduction plans on Tehran air quality using WRF/CAMx modeling tools. Transportation Research Part D: Transport and Environment, 57, pp. 484-495, 2017.

[12] Emmons, L.K. et al., Description and evaluation of the Model for Ozone and Related chemical Tracers, version 4 (MOZART-4), 2010.

[13] Silveira, C., Ferreira, J., Monteiro, A., Miranda, A.I. \& Borrego, C., Emissions from residential combustion sector: how to build a high spatially resolved inventory. Air Quality, Atmosphere \& Health, 2017.

[14] Borrego, C., Tchepel, O., Salmim, L., Amorim, J., Costa, A. \& Janko, J., Integrated modeling of road traffic emissions: application to Lisbon air quality management. Cybernetics and Systems: An International Journal, 35(5)-(6), pp. 535-548, 2004.

[15] Carnevale, C., Finzi, G., Guariso, G., Pisoni, E. \& Volta, M., Surrogate models to compute optimal air quality planning policies at a regional scale. Environmental Modelling \& Software, 34, pp. 44-50, 2012. 